\title{
Design and Development of Transdermal Patches of Antipsychotic Drug: In vitro and Ex vivo Characterization
}

\author{
Anjaneyulu Rajagoni ${ }^{1}$, Preethi Pagilla ${ }^{1}$, Jerusha Perumala ${ }^{1}$, Shilpa Puppala ${ }^{1}$, \\ Himabindu Peddapalli ${ }^{1 *}$, Katta Sunand ${ }^{2}$, Vasudha Bakshi ${ }^{1,2}$ \\ ${ }^{1}$ Department of Pharmaceutics, School of Pharmacy, Anurag University, Ghatkesar-500088, Telangana, India \\ ${ }^{2}$ Department of Pharmacology, School of Pharmacy, Anurag University, Ghatkesar-500088, Telangana, India
}

\begin{abstract}
The purpose of the present research work was to design, assess, and estimate the developed transdermal matrix-type formulation comprising levosulpiride hydrochloride with the objective of enhancing the bioavailability and compliance of the patient. Transdermal films of levosulpiride were developed using a solvent casting method by hydroxypropyl methylcellulose (HPMC) E 15, Eudragit RL 100, and Eudragit RS100. In current research work, propylene glycol and oleic acid was used as plasticizer and permeation enhancers in different fractions. Among the batches, drug content uniformity with all formulations was perceived between 91.6 to $98 \%$. Folding endurance of patches was good and indicates satisfactory flexibility. Developed transdermal films had the necessary physicochemical properties, for example, uniformity of drug content, weight, thickness, folding endurance, and dampness content. Franz diffusion cell was used for in vitro diffusion studies utilizing dialysis membrane as a pervasion boundary. Formulation F5 (Eudragit RL 100-1\%, HPMC E15-9\%) was found to be best among all batches of its consistent release rate for 12 hours and the extent of drug release $97.76 \%$. F5 was the most palatable formulation as it firmly meets the standards and continuously permeated drugs for 12 hours that can keep up desired therapeutic concentration in plasma. The patches were exposed to transient stability studies and were observed to be constant and stable.
\end{abstract}

Keywords: Eudragit RL 100, Hydroxypropyl methylcellulose (HPMC), In vitro permeation, Levosulpiride hydrochloride, Transdermal patches.

\section{INTRODUCTION}

Delivery of medications through the skin has been consistently a challenging field for researchers because of obstructive barrier properties of the skin. Over the most recent twenty years, the transdermal drug delivery system has emerged as the most consistent, as well as, viable innovation that offers huge clinical advantages over other dosage forms. Transdermal drug delivery system (TDDS) involves the permeation of the drug across the skin surface on the application and arrives at the systemic circulation in adequate quantity. ${ }^{1}$ Controlled drug release can be accomplished by TDDS which can transfer the drug in a therapeutically effective amount through the skin portal over an extended time period. ${ }^{2,3}$ Additionally, it is expedient, safe, and overcomes different adverse effects, such as, first-pass metabolism and painful delivery of the drugs associated with other drug delivery systems. The transfer of drugs can be dismissed at any point in TDDS by eliminating the transdermal system. The drug should have many physicochemical properties, such as, low molecular weight, small half-life, high lipophilicity, low dose, and less oral bioavailability to be formulated as transdermal drug delivery. ${ }^{4,5}$

Levosulpiride is a selective dopamine $\mathrm{D}_{2}$ antagonist used in the treatment of schizophrenia, anxiety disorders, dyspepsia, irritable bowel syndrome, and gastroesophageal reflux disease. The molecular weight of the drug is $341.426 \mathrm{~g} / \mathrm{mol}$ and has a plasma half-life of about 6 to 8 hours. It is quickly metabolized by the liver which lowers its oral bioavailability to $30 \%,{ }^{6,7}$ because of which there is a need to develop a controlled drug delivery system to reach the therapeutic target. Furthermore, with the low molecular weight of levosulpiride, it can be loaded onto a transdermal patch which can be easily absorbed across the skin.

\section{Corresponding author}

Himabindu Peddapalli

Email : himabindupharmacy@cvsr.ac.in 


\section{MATERIALS AND METHODS}

\subsection{Drugs, Chemicals, and Instruments}

The pure drug levosulpiride was acquired as a gift sample from Delta Finochem Pvt. Ltd., Nasik, Maharashtra, India. Eudragit RL100, Eudragit RS100, and oleic acid were purchased from Central Scientific Supplies Co. Ltd., Hyderabad, India. HPMC E15 was purchased from Central Drug House (P) Ltd., New Delhi, India. Propylene glycol was obtained from Fine Chemicals, Chandigarh, India. Dichloromethane and methanol were purchased from Rankem Fine Chemicals Ltd., New Delhi, India.

\subsubsection{Instruments}

Digital weigh balance (Infra Digi, Chennai, India); pH meter (Infra Digi, Chennai, India); magnetic stirrer (Indosati, Haryana, India), ultra sonicator (Citizen, Gujarat, India); hot air oven (Cintex, Maharashtra, India); Franz diffusion cell (Able Glass, Hyderabad, India); UV spectrophotometer (UV-3200, Lab India, Hyderabad, India).

\subsection{Preformulation Studies of the selected Drug}

\subsubsection{Solubility Determination}

The solubility of levosulpiride was measured in distilled water and phosphate buffer of $\mathrm{pH}$ 7.4. The excess quantity of the levosulpiride was taken in a glass beaker and dissolved in a measured quantity of above solvents independently to get a saturated solution. The remaining drug particles were shaken alternatingly. Then, the determined quantity of filtered drug solution was withdrawn after 24 hours, diluted with corresponding solvents, and concentration was calculated spectrophotometrically. ${ }^{8}$

\subsubsection{Melting Point Determination}

A small quantity of the drug was incorporated in a capillary tube closed at one end and placed in the Thiele melting point apparatus. The temperature at which the drug melts was recorded. ${ }^{9}$

\subsubsection{Preparation of Standard Graph of Levosulpiride}

The stock solution of levosulpiride was prepared by dissolving $100 \mathrm{mg}$ of levosulpiride in a $100 \mathrm{~mL}$ volumetric flask with phosphate buffer ( $\mathrm{pH}$ 7.4). For obtaining the solution of $1,000 \mu \mathrm{g} / \mathrm{mL}$ strength, the solution was made up to the mark using the same phosphate buffer (stock I). To obtain a solution of $100 \mu \mathrm{g} / \mathrm{mL}$ strength, $10 \mathrm{~mL}$ of the stock I solution was diluted to $100 \mathrm{~mL}$ of distilled water (stock II). From stock II solution, secondary stocks of concentrations $0.2,0.4,0.8,1,2,3,4,5$, and $6 \mathrm{~mL}$ were taken separately and made up to $10 \mathrm{~mL}$ with phosphate buffer (pH 7.4) to produce 2, 4, 8, 10, 20, 30, 40, 50, and $60 \mu \mathrm{g} / \mathrm{mL}$, respectively. The absorbance was measured at $262 \mathrm{~nm}$ using a UV-visible spectrophotometer.

\subsubsection{Fourier Transform Infrared (FTIR) Drug Excipients Compatibility Studies}

The spectrum for the samples was obtained using the potassium bromide (KBr) disk method by the FTIR spectrophotometer. Pure drug levosulpiride alone, a mixture of levosulpiride and HPMC E15, mixture of levosulpiride and Eudragit RL100, and a mixture of levosulpiride and Eudragit RS100 were prepared and exposed to FTIR studies. Approximately $2 \mathrm{mg}$ of sample was mixed with an equal weight of dried $\mathrm{KBr}$ and trampled to get a $\mathrm{KBr}$ disk. The samples were measured in the spectral region with a resolution of $4 \mathrm{~cm}^{-1}$ from 400 to $4,000 \mathrm{~cm}^{-1}$.

\subsection{Formulation Development of Transdermal Patches}

The levosulpiride matrix-type transdermal patches were prepared by the solvent casting method with HPMC E15, Eudragit RL100, and Eudragit RS100 as mucoadhesive polymers, dichloromethane:methanol (1:1) as a solvent system, propylene glycol (PG) as a plasticizer, and oleic acid was used as a permeation enhancer. Weighed quantities of HPMC E15, Eudragit RS100, and Eudragit RL100, as shown in Table 1, were taken in a boiling tube. In this, $25 \mathrm{~mL}$ of a mixture of solvents, i.e., dichloromethane:methanol in the ratio 1:1 was incorporated and vortexed. Appropriate precautions were undertaken to avert the development of lumps. The boiling tube was kept separately for swelling of polymer for a period of 5 hours. After efficient swelling, weighed quantities of propylene glycol and penetration enhancers were incorporated and again vortexed. Lastly, a measured amount of levosulpiride dissolved in sufficient solvent was added to the solution of polymer and mixed well. It was then kept aside to eliminate air bubbles for a short period. Then, the gel was moved into cleaned Petri plates. These patches were dried over a horizontal surface in an oven for 24 hours, till a springy film was formed. After overnight, the dried patches (Figure 1) were carefully

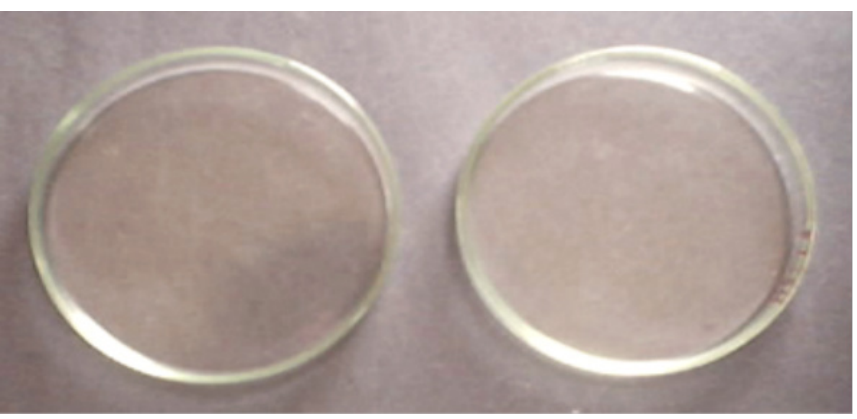

Figure 1: Casting of transdermal patches of levosulpiride 
removed. These developed patches were cut into small square-shaped pieces, each patch having an area $2.25 \mathrm{~cm}^{2}$, and were packed in aluminum foil until the evaluation assessments were accomplished. ${ }^{10,11}$

\subsection{Evaluation of Developed Transdermal Patches}

\subsubsection{Physical Appearance}

All the developed transdermal patches of levosulpiride were assessed for color, clarity, flexibility, and smoothness.

\subsubsection{Weight Variation}

Ten patches from each batch were selected and weighed separately on a digital balance. The average weight and standard deviation were estimated. The percent deviation was calculated using the following formula.

$$
\% \text { deviation }=\frac{\text { Individual weight }- \text { Average weight }}{\text { Average weight }} \times 100
$$

\subsubsection{Film Thickness}

The patch thickness was measured at altered points of the patch by using a screw gauge.

\subsubsection{Folding Endurance}

Folding endurance of the developed patches was assessed by constantly folding a patch at a similar space up until it brakes. The number of times of patch could be folded at the same spot deprived of breaking gave the estimation of the folding endurance of the patch, which was viewed as agreeable to reveal good folding patch properties. ${ }^{8,9,12}$ The results are reported in Table 2.

\subsubsection{Surface $\mathrm{pH}$ of Patches}

The method adopted by Peddapalli et al., 2017 was used to measure the surface $\mathrm{pH}$ of the patches which employs a joined glass electrode. The transdermal patch was made in contact with $1 \mathrm{~mL}$ of distilled water and permitted to expand for 2 hours at room temperature. The surface $\mathrm{pH}$ was then determined by keeping the $\mathrm{pH}$ electrode on the surface of the patch and allowed to equilibrate for 1-minute. ${ }^{11}$ The results are reported in Table 2.

\subsubsection{Content Uniformity of the Patches}

For drug content uniformity, the developed patches were assayed in each case. Three patches equivalent to $2.25 \mathrm{~cm}^{2}$ area from each formulation were assayed for the content of the drug. Patches from each formulation were cut into small pieces, dissolved in $100 \mathrm{~mL}$ of phosphate buffer ( $\mathrm{pH}$ 7.4) taken into a conical flask. The solution was then filtered through $0.45 \mu \mathrm{m}$ filter paper and diluted with phosphate buffer ( $\mathrm{pH}$ 7.4). The drug content was estimated using a UV-visible spectrophotometer at $262 \mathrm{~nm} .{ }^{10}$

\subsubsection{Moisture Absorption Studies}

The moisture absorption studies give a sign about the relative dampness assimilation limits of polymers and thought of whether the developed formulation keeps up its integrity after retention of dampness. $5 \% \mathrm{w} / \mathrm{v}$ agar was taken in hot distilled water, moved into Petri plates,

Table 1: Composition of levosulpiride transdermal patches

\begin{tabular}{lllllll}
\hline $\begin{array}{l}\text { Formulation } \\
\text { code }\end{array}$ & $\begin{array}{l}\text { Amount of } \\
\text { drug }(\mathrm{mg})\end{array}$ & $\begin{array}{l}\text { Drug: polymer (Eudragit } \\
\text { RS100: HPMC E15) }\end{array}$ & $\begin{array}{l}\text { Drug: polymer (Eudragit } \\
\text { RL100: HPMC E15) }\end{array}$ & $\begin{array}{l}\text { \% of } \\
\text { oleic acid }\end{array}$ & $\begin{array}{l}\text { \% of } \\
\text { propylene glycol }\end{array}$ & $\begin{array}{l}\text { Amount of } \\
\text { solvent (mL) }\end{array}$ \\
\hline F1 & 5 & $5: 5$ & - & 10 & 0 & 30 \\
F2 & 5 & $3: 7$ & - & 20 & 30 & 30 \\
F3 & 5 & $2: 8$ & - & 20 & 30 & 30 \\
F4 & 5 & $2: 6$ & - & 20 & 30 & 30 \\
F5 & 5 & - & $1: 8$ & 20 & 30 & 30 \\
F6 & 5 & - & $2: 6$ & 20 & 30 & 30 \\
F7 & 5 & - & $3: 7$ & 20 & 30 & 30 \\
F8 & 5 & - & $4: 6$ & 20 & 30 & 3
\end{tabular}

Table 2: Physicochemical parameters of transdermal patches of levosulpiride

\begin{tabular}{lllllll}
\hline $\begin{array}{l}\text { Formulation } \\
\text { code }\end{array}$ & $\begin{array}{l}\text { Weight } \\
\text { variation }(\mathrm{mg})\end{array}$ & $\begin{array}{l}\text { Film } \\
\text { thickness }(\mathrm{mm})\end{array}$ & $\begin{array}{l}\text { Folding } \\
\text { endurance }\end{array}$ & $\begin{array}{l}\text { \% content } \\
\text { uniformity }\end{array}$ & Surface pH & $\begin{array}{l}\text { \% moisture } \\
\text { absorption studies }\end{array}$ \\
\hline F1 & $93 \pm 0.043$ & $0.19 \pm 0.1$ & $142 \pm 9$ & $91.6 \pm 3.5$ & $5.63 \pm 0.25$ & $79.6 \pm 2.21$ \\
F2 & $95 \pm 0.026$ & $0.25 \pm 0.3$ & $130 \pm 2.1$ & $93.5 \pm 2.8$ & $5.73 \pm 0.64$ & $67.2 \pm 5.29$ \\
F3 & $90 \pm 0.068$ & $0.24 \pm 0.6$ & $120 \pm 6.2$ & $92.6 \pm 1.9$ & $6.68 \pm 0.68$ & $59.35 \pm 3.61$ \\
F4 & $92 \pm 0.005$ & $0.23 \pm 0.2$ & $106 \pm 4.1$ & $95.7 \pm 3.6$ & $7.12 \pm 0.47$ & $48.4 \pm 1.46$ \\
F5 & $92 \pm 0.01$ & $0.2 \pm 0.4$ & $153 \pm 2$ & $98.0 \pm 2.9$ & $7.04 \pm 0.34$ & $81.2 \pm 2.04$ \\
F6 & $91 \pm 0.047$ & $0.21 \pm 0.04$ & $113 \pm 1.3$ & $96.1 \pm 6.8$ & $5.68 \pm 0.38$ & $71.5 \pm 2.21$ \\
F7 & $95 \pm 0.015$ & $0.27 \pm 0.2$ & $126 \pm 1.5$ & $95.7 \pm 4.6$ & $6.18 \pm 0.58$ & $65.7 \pm 2.21$ \\
F8 & $92 \pm 0.03$ & $0.22 \pm 0.3$ & $113 \pm 3$ & $97.9 \pm 3.8$ & $6.8 \pm 0.41$ & $50.9 \pm 2.21$ \\
\hline
\end{tabular}

Each value represents the mean $\pm \operatorname{SD}(n=3)$ 
and permitted to harden. At that point, six patches from every formulation were nominated and weighed. They were set on the surface of the agar and incubated at $37^{\circ} \mathrm{C}$ for two hours in an incubator. The patches were taken out and weighed once more. The level of dampness assimilated can be determined utilizing the accompanying equation. ${ }^{21}$

$$
\% \text { moisture absorbed }=\frac{\text { Final weight }- \text { Initial weight }}{\text { Initial weight }} \times 100
$$

\subsubsection{In vitro Drug Diffusion Studies}

In vitro diffusion studies were carried out by utilizing the Franz diffusion apparatus (Figure 2). The dialysis film was kept in between the contributor and receptor compartment of the diffusion apparatus. The film was set on a cellulose acetic acid derivation layer and secured with aluminum foil. The receptor compartment of the dissemination cell was loaded up with phosphate buffer ( $\mathrm{pH}$ 7.4). The entire assembly was fixed on a hot plate magnetic stirrer and the solution in the receptor compartment was continually and persistently mixed utilizing magnetic beads. The temperature was maintained at $37 \pm 0.5^{\circ} \mathrm{C}$. The samples were pulled back at various times spans up to 12 hours and examined for drug content spectrophotometrically. The receptor stage was renewed with an equivalent volume of phosphate buffer at each sample withdrawal. ${ }^{13,14}$

\subsubsection{Release Kinetic Modeling}

A suitable drug discharge test is needed to portray the drug product, ensure batch to batch reproducibility, reliable pharmacological activity, and post-approval modifications. The discharge of drugs from a sustained release formulation is constrained by different variables, such as, erosion or diffusion. A few mathematical models were proposed by numerous analysts to depict the medication discharge profiles from different systems. The model depends upon a bend fitting system. Distinctive mathematical functions have been utilized to

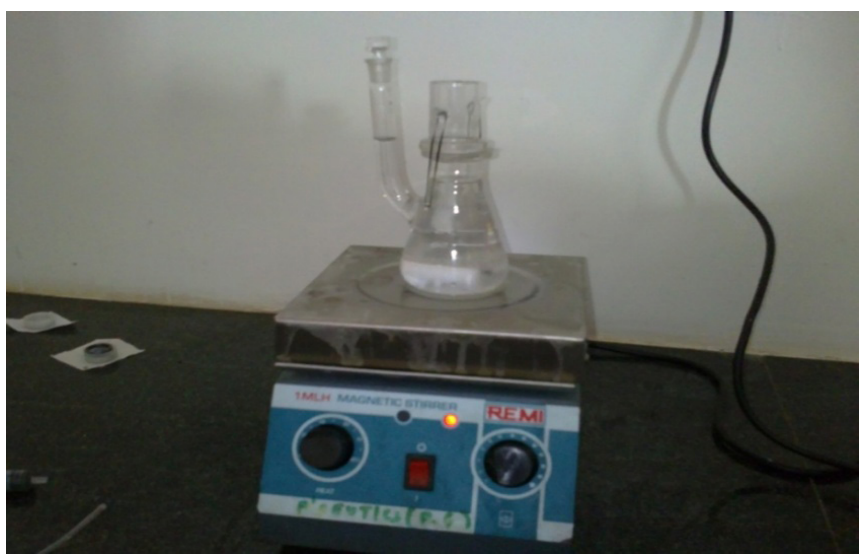

Figure 2: In vitro drug release studies by using Franz diffusion cell model the observed information. Both the linear and non-linear models are being utilized in practice for dissolution modeling. Linear models incorporate zero-order, Higuchi, Hixson-Crowell, and quadratic and polynomials, whereas the nonlinear models incorporate first-order, Weibull, Korsmeyer-Peppas, logistic, etc.

The principal example of a mathematical model intended to portray drug discharge from a matrix system was proposed by Higuchi in 1961. This is the most generally utilized model to portray drug discharge from drug matrices. Korsmeyer et al., 1983 inferred a basic relationship that depicted medication discharge from a polymeric system equation. To discover the system of medication discharge, the first $60 \%$ of medication discharge data were fitted in Korsmeyer-Peppas model. ${ }^{15,16}$

$$
\mathrm{M}_{\mathrm{t}} / \mathrm{M}_{\infty}=\mathrm{Kt}^{\mathrm{n}}
$$

Where $M_{t} / M_{\infty}$ is a fraction of drug released at time $t, K$ is the delivery rate constant, and $\mathrm{n}$ is the release exponent. The $\mathrm{n}$ value is utilized to describe the distinctive delivery mechanism for cylindrical shaped matrices.

In this model, the estimation of $\mathrm{n}$ portrays the release mechanism of drugs. For the case of cylindrical tablets, $0.45 \leq n$ corresponds to a Fickian diffusion mechanism, $0.45<\mathrm{n}<0.89$ to non-Fickian transport, $\mathrm{n}=0.89$ compares to case II (relaxational) transport, and $n>0.89$ to super case II transport. To study the release kinetics, data acquired from in vitro drug release studies were plotted as $\log$ cumulative percentage drug release $v s$. $\log$ time. $^{17}$

\subsubsection{Ex vivo Skin Permeation Studies}

In vitro skin permeation studies were performed utilizing an altered Franz dissemination apparatus with a diffusion area of $2.25 \mathrm{~cm}^{2}$. The extracted abdominal skin of the rodent was mounted between the donor and receptor compartments of the diffusion apparatus. The defined patches were set over the skin and shrouded with paraffin film so as to ensure that the patches do not oust from the skin during the test. The receptor compartment of the dissemination cell was loaded up with phosphate buffer $(\mathrm{pH}$ 7.4). The entire assembly was fixed on a magnetic stirrer and the solution in the receptor compartment was continuously stirred utilizing magnetic beads at $50 \mathrm{rpm}$; the temperature was kept up at $32 \pm 0.5^{\circ} \mathrm{C}$ so as to simulate skin temperature. At predetermined time intervals for a total of 12 hours, aliquots were withdrawn and the receptor compartment was recharged with an equivalent volume of phosphate buffer $(\mathrm{pH}$ 7.4) at each sample withdrawal. The drug content in the withdrawn sample was determined spectrophotometrically at $262 \mathrm{~nm} \cdot{ }^{10,18}$

\subsubsection{Measurement of Mechanical Properties}

Mechanical properties of the developed transdermal patches were assessed utilizing a microprocessor-based advanced force gauze equipped with a motorized test 
stand (Ultra Test, Mecmesin, West Sussex, UK), furnished with a $25 \mathrm{~kg}$ load cell. The film strip with the measurements $60 \times 10 \mathrm{~mm}$ and liberated from air bubbles or physical defects, was held between two clamps situated at a distance of $3 \mathrm{~cm}$. The cardboard was attached on the surface of the clamp to keep the film from being cut by the depressions of the clip. During estimation, the strips were pulled by the top clamp at a pace of $2 \mathrm{~mm} /$ sec to a distance, till the film broke. The power and extension were estimated when the films were broken. Results from film samples, which were broken toward the end and not between the clamps, were excluded from observations. The accompanying equations were utilized to ascertain the mechanical properties of the films. ${ }^{11}$

Tensile strength $\left(\mathrm{kg} \cdot \mathrm{mm}^{-2}\right)=\frac{\text { Force at break }(\mathrm{kg})}{\text { Initial cross- sectional area of the sample }\left(\mathrm{mm}^{2}\right)}$
Elongation at break $\left(\% \mathrm{~mm}^{-2}\right)=\frac{\text { Increase in length }(\mathrm{mm})}{\text { Original length } \times \text { Cross- sectional area }\left(\mathrm{mm}^{2}\right)} \times 100$

\subsubsection{In vitro-Ex vivo Correlation between}

Cumulative \% Drug Released In vitro and

$\%$ Drug Permeated Ex vivo of Optimized

Transdermal Patch of Levosulpiride

A possible in vitro-ex vivo correlation was performed for $\%$ drug released in vitro and $\%$ drug permeated ex vivo for optimized formulation. ${ }^{10,11}$

\subsubsection{Stability Studies}

The reason for stability testing is to give proof about the quality of a drug substance or drug product fluctuates with time affected by an assortment of ecological factors, for example, temperature, humidity, and light, and to build up a re-trial for the medication substance or shelf life for the drug product and suggested storage conditions. Stability studies were carried for the most acceptable formulation. The most satisfactory formulation is stored and sealed in aluminum foil. These were stored at room temperature for 2 months and afterward assessed for folding endurance, content uniformity, and in vitro release of the drug. 19,20

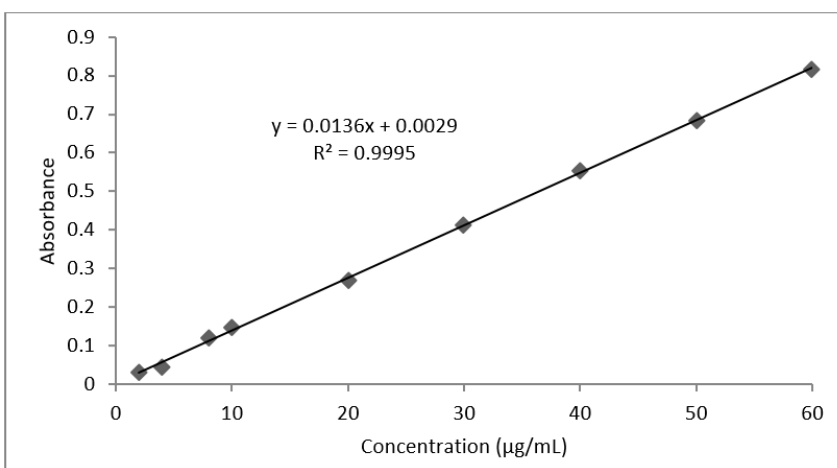

Figure 3: Standard graph of levosulpiride in $\mathrm{pH} 7.4$ phosphate buffer

\section{RESULTS AND DISCUSSION}

\subsection{Preformulation Studies}

\subsubsection{Solubility and Melting Point Determination}

The solubility of the drug in water and phosphate buffer at $\mathrm{pH} 7.4$ was observed to be 0.439 and $0.825 \mathrm{mg} / \mathrm{mL}$, respectively. The melting point of levosulpiride was found to be $185^{\circ} \mathrm{C}$.

\subsubsection{Standard Graph of Levosulpiride}

Different concentrations were prepared in phosphate buffer $7.4(2-60 \mu \mathrm{g} / \mathrm{mL})$ and absorbance values at $\lambda_{\max }(262 \mathrm{~nm})$ were noted. The calibration curves displayed a correlation coefficient of $\mathrm{R}^{2} 0.9995$ and good linearity (Figure 3).

\subsubsection{FTIR Drug Excipients Compatibility Studies}

Probable chemical interfaces among the drug and polymer may change the therapeutic efficiency of the drug for which FTIR spectroscopic studies were performed over the range of 400 to $4,000 \mathrm{~cm}^{-1}$. The FTIR spectrum of levosulpiride and polymers is given in Figures 4 to 7 separately, which validates sharp transmittance bands for $(\mathrm{C}-\mathrm{H})$ at $2,810 \mathrm{~cm}^{-1}$. The characteristic bands of $\mathrm{OH} / \mathrm{NH}$ groups in levosulpiride at 3,124 and $3,367 \mathrm{~cm}^{-1}$ shifted to short and extensive peaks, which portrays the association of these groups in interfacial $\mathrm{H}$-bonding between the components. The other significant commitments from levosulpiride are the existence of an amide band consistent with $\mathrm{C}=\mathrm{O}$ vibration of the acetyl group at $\sim 1,623 \mathrm{~cm}^{-1}$ and $\mathrm{C}-\mathrm{N}$ stretching vibration at $1,060 \mathrm{~cm}^{-1}$. These FTIR bands of the drug stay together in both the spectra of the drug and physical blend, outlining the absence of association among drug and mucoadhesive polymers utilized (Figures 4 to 7).

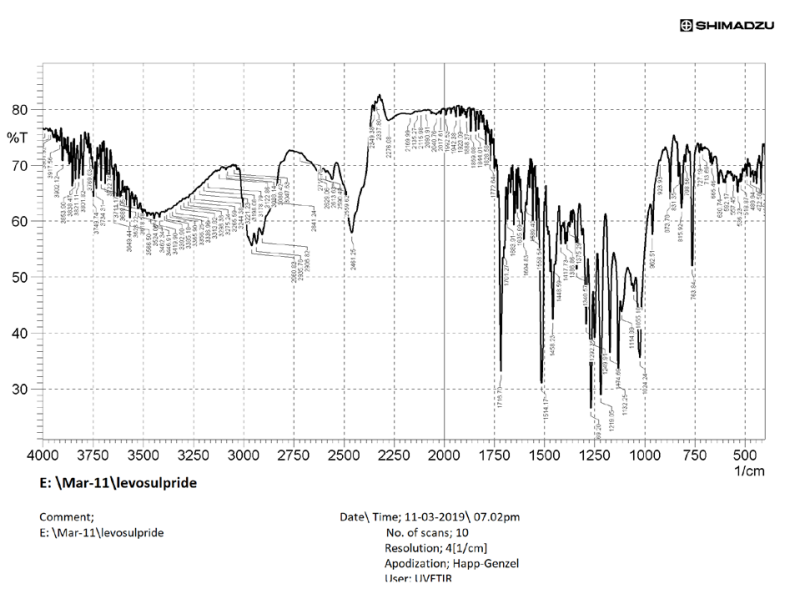

Figure 4: FTIR spectrum of pure levosulpiride 


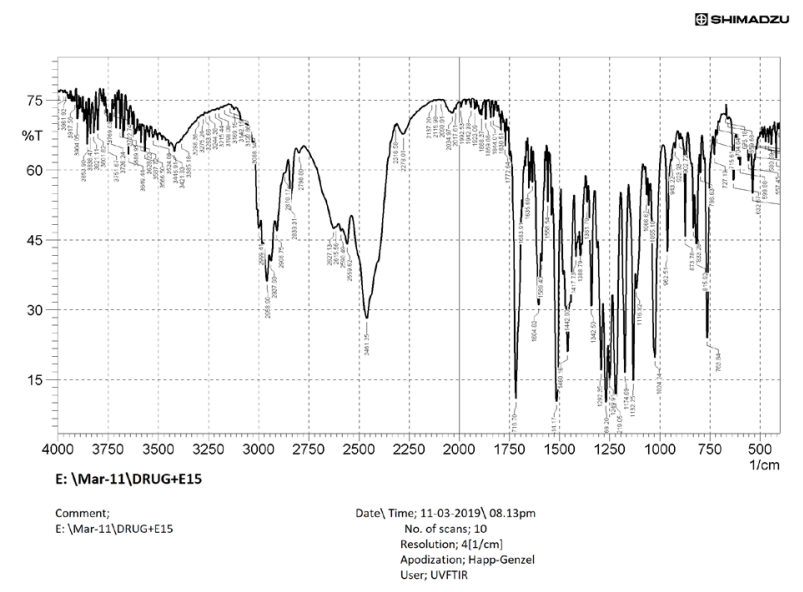

Figure 5: FTIR spectrum of pure levosulpiride and HPMC E15

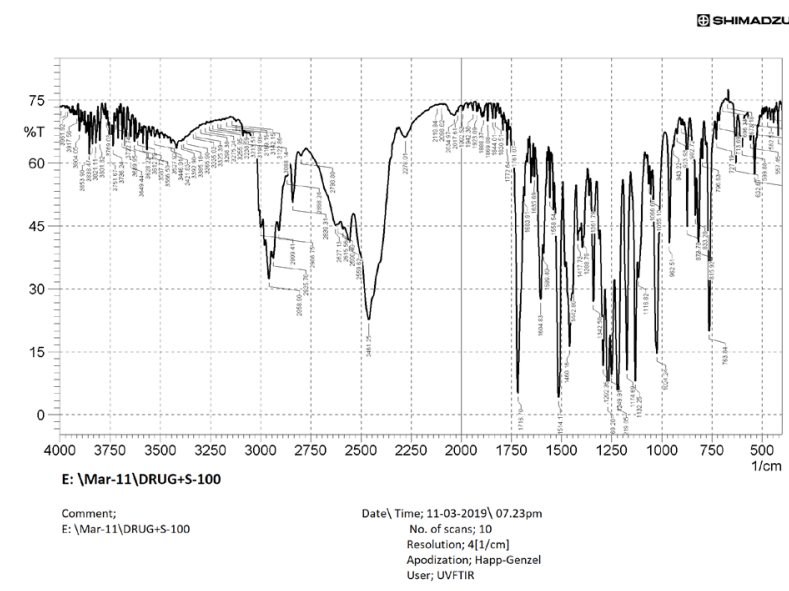

Figure 6: FTIR spectrum of pure levosulpiride and Eudragit RS100

\subsection{Evaluation of the Developed Transdermal Patches}

Transdermal patches of levosulpiride were successfully prepared by the solvent casting method utilizing various polymers in dissimilar combinations and proportions.

\subsubsection{Weight, Thickness, and Drug Uniformity}

The formulated patches were found to be smooth, elegant in appearance, uniform in thickness, weight, and drug content. The patches showed no visible cracks and have efficient folding endurance property. The weight of the patches from 91 to $95 \mathrm{mg}$ indicates an increase in weight with an increase in polymer concentration in formulations. The thickness ranged from 0.19 to $0.27 \mu \mathrm{m}$ and was found to be increased with growth in the concentration of polymer. The concentration of drug in the patches was found to be uniformly dispersed all over the patches in the range of 91.6 to $98 \%$. All these parameters were within acceptable limits. The results were shown in Table 2.

\subsubsection{Surface $p H$ Study}

Surface $\mathrm{pH}$ was measured so as to examine the probability of in vivo adverse effects. As alteration in $\mathrm{pH}$ causes

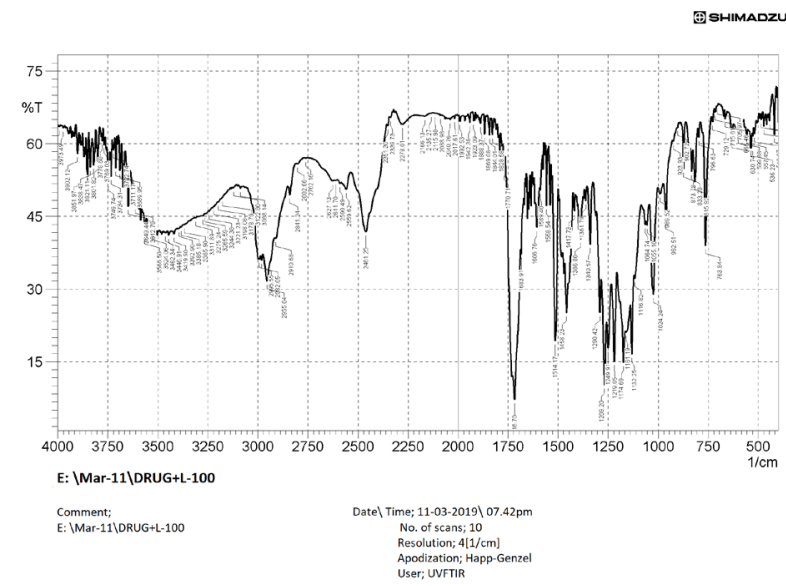

Figure 7: FTIR spectrum of pure levosulpiride and Eudragit RL100

irritation to the skin, it is necessary to retain the surface $\mathrm{pH}$ neutral. The surface $\mathrm{pH}$ of all the formulated patches was found to be in the acceptable range of 5.63 to 7.12 . Therefore, the formulated patches do not cause any irritation to the skin. The results were shown in Table 2.

\subsubsection{Moisture Absorption Studies}

The results of moisture absorption studies were introduced in Table 2. Rate dampness consumed values ran from about 48.4 to $81.2 \% \mathrm{w} / \mathrm{w}$. At the point when the patches were put without support film, total expansion followed by disintegration was observed demonstrating that the medication discharge system includes growing of the polymer at first, followed by drug discharge from the swollen matrix by diffusion. The results were shown in Table 2.

\subsubsection{In vitro Diffusion Study}

In vitro diffusion studies of the developed levosulpiride patches were carried out by using the dialysis membrane and diffusion cell in phosphate buffer $(\mathrm{pH}$ 7.4) solution. In the case of $\mathrm{F} 1$ to $\mathrm{F} 4$ formulations, the drug release was retarded due to the presence of high retarding polymer Eudragit RS 100 and followed by slow release and showed about $35.7 \pm 3.14,53.63 \pm 2.16,64.8 \pm 0.96$, and $84.71 \pm 3.68 \%$ in 12 hours, respectively. The formulations F5, F6, F7, and F8 had shown $97.76 \pm 2.87,93.45 \pm 1.66,88.35 \pm 2.11$, and $84.33 \pm 1.87 \%$ in 12 hours, respectively. No significant difference in the final calculation of drug release was observed. It is clear, well-defined from the plots that the release of drugs was directed by the concentration of polymer. Formulations F1 to F4 prepared from Eudragit RS 100, exhibited the lowest percentage of drug release values, when in contrast with the values detected with the formulations comprising Eudragit RL 100 and as the concentrations of hydrophilic polymer (HPMC) increased in the formulations, the drug release rate increased substantially. Eudragit RL 100 is extensively utilized in a controlled release system and bioavailability 
development methodologies compared to Eudragit RS100. Among all formulations, F5 showed maximum release with a sustained rate and was found to be the most satisfactory formulation. The drug release summary from transdermal patches is revealed in Figure 8, respectively, for formulation F1 to F8.

\subsubsection{Kinetics Models}

In vitro drug release data were corresponded to zero order, first order, Higuchi, and Korsmeyer-Peppas equations to determine the drug release pattern of levosulpiride from transdermal patches. It was perceived that when the concentrations of hydrophilic polymer increased in the formulations, the rate of drug release also increased substantively, and Eudragit RS 100 displayed the lowest amount of drug release in contrast with the drug release rate formulated with Eudragit RL 100. The drug release profiles were described by a model function utilizing various kinetic studies. Higuchi square root was found to be the best model portraying kinetics from all patches. Besides, $n$ values $(0.721 \leq n \geq 1.012)$ specified released drug amount was by non-Fickian diffusion. The results are shown in Table 3.

\subsubsection{Ex vivo Skin Permeation Studies of Optimized Formulation}

The experimental protocol of the ex vivo skin permeation study was permitted by the Institutional Ethical Committee, Anurag University, with protocol number I/IAEC/ AGI/006/2019WR $\widehat{o}+$ q . The formulation F5 was selected as the optimized formulation for studying the ex vivo permeation studies because of its satisfactory in vitro drug release, ability to keep the structure in dampness absorption studies, and in vitro bio-adhesion studies. The outcomes of drug permeation through the rat membrane exposed that drug was released and permeated through the rat membrane and later can be permeated through the human skin membrane. The results showed that $65.78 \pm 2.47 \%$ of levosulpiride could pass through the skin membrane from the optimized formulation in 12 hours, and the cumulative percentage amount of levosulpiride that had penetrated through the rat epithelium from the patch was shown in Figure 9.

\subsubsection{Measurement of Mechanical Properties}

A good transdermal patch must be elastic, adaptable, and sufficiently robust to endure rupture because of stress-

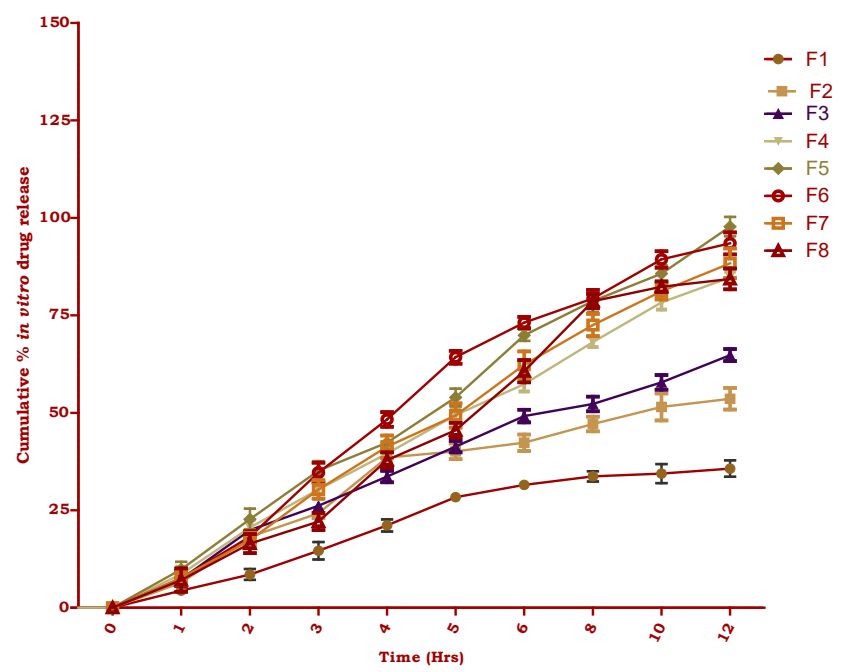

Figure 8: Comparative in vitro diffusion study of all formulations ${ }^{*} \mathrm{n}=3$, studies were repeated in triplicate, and the mean was calculated.

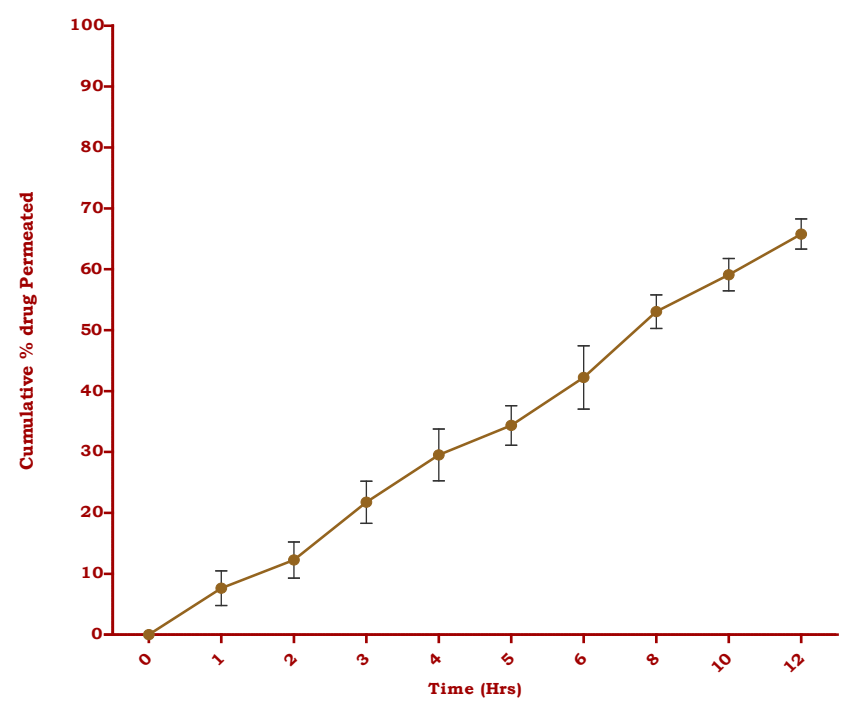

Figure 9: Ex vivo cumulative \% of drug permeation studies of most satisfactory formulation

Table 3: Kinetic models for in vitro release of levosulpiride from formulations F1 to F8

\begin{tabular}{|c|c|c|c|c|}
\hline & Zero-order & First-order & Higuchi & Korsmeyer-Peppas \\
\hline Formulation & $R^{2}$ & & & $N$ \\
\hline $\mathrm{F} 1$ & 0.8075 & 0.9763 & 0.9241 & 0.8376 \\
\hline F2 & 0.8279 & 0.9578 & 0.9379 & 0.7893 \\
\hline F3 & 0.8453 & 0.9557 & 0.9289 & 0.8321 \\
\hline F4 & 0.8519 & 0.948 & 0.9002 & 0.8458 \\
\hline F5 & 0.8473 & 0.9897 & 0.9521 & 0.7392 \\
\hline F6 & 0.8604 & 0.9602 & 0.9314 & 0.7954 \\
\hline F7 & 0.8567 & 0.9424 & 0.9321 & 0.7982 \\
\hline F8 & 0.8542 & 0.9643 & 0.9271 & 0.832 \\
\hline
\end{tabular}


Table 4: Physicochemical properties of most satisfactory formulations (after stability)

\begin{tabular}{lll}
\hline Formulation code & $F 5$ at $40 \pm 2^{\circ} \mathrm{C} / 75 \pm 5 \% \mathrm{RH}$ & \\
\hline Time (days) & 30 days & 60 days \\
Folding endurance & $140.66 \pm 7.6$ & $135 \pm 11.01$ \\
$\%$ content uniformity & $97.04 \pm 1.15$ & $95.19 \pm 3.96$ \\
$\%$ moisture absorption & $87.8 \pm 1.47$ & $86.4 \pm 0.91$ \\
\hline
\end{tabular}

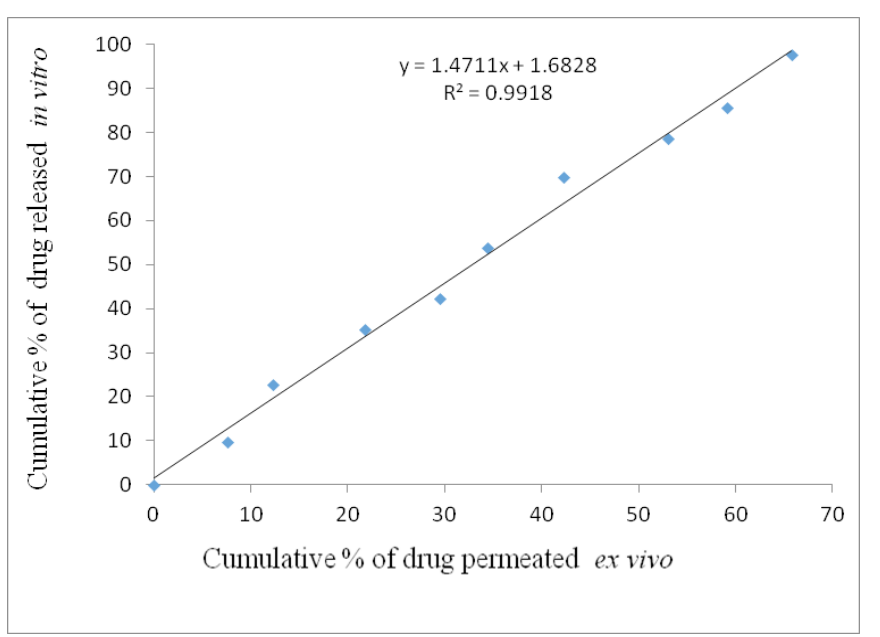

Figure 10: Correlation between in vitro and ex vivo drug release of the optimized formulation

triggered while handling on the surface of the skin. The tensile strength and elongation at break studies showed the strength and elasticity of the films. Tensile strength improved with an increase in the content of polymer; however, elongation at break values reduced with an increase in the content of the polymer. The optimized formulation F5 exhibited a tensile strength of $12.3 \pm 1.14$ $\mathrm{kg} / \mathrm{mm}^{2}$ and elongation at break of $34.5 \pm 2.04 \% \mathrm{~mm}^{2}$.

\subsubsection{In vitro Ex vivo Correlation between Cumulative \% Drug Released In vitro and $\%$ Drug Permeated Ex vivo of Optimized Formulation of Transdermal Patch}

Cumulative \% of drug released ex vivo through the rat skin was interrelated in contradiction of cumulative \% of drug released using in vitro release tests for optimized formulation F5. Figure 10 showed the association between the $e x v i v o \%$ and in vitro $\%$ of drug released. The linear line and correlation coefficient of 0.9918 showed a good correlation between in vitro and ex vivo drug release studies. Therefore, it can be established that the developed transdermal patches can be designed to improve bio availability.

\subsubsection{Stability Study of Most Satisfactory} Formulation

The most satisfactory formulation F5 was subjected to stability studies by sealing it in aluminum foil and stockpiled in the stability chamber. These were stored at room temperature for 2 months, after which the concentration of the drug was determined. From Table 4 and

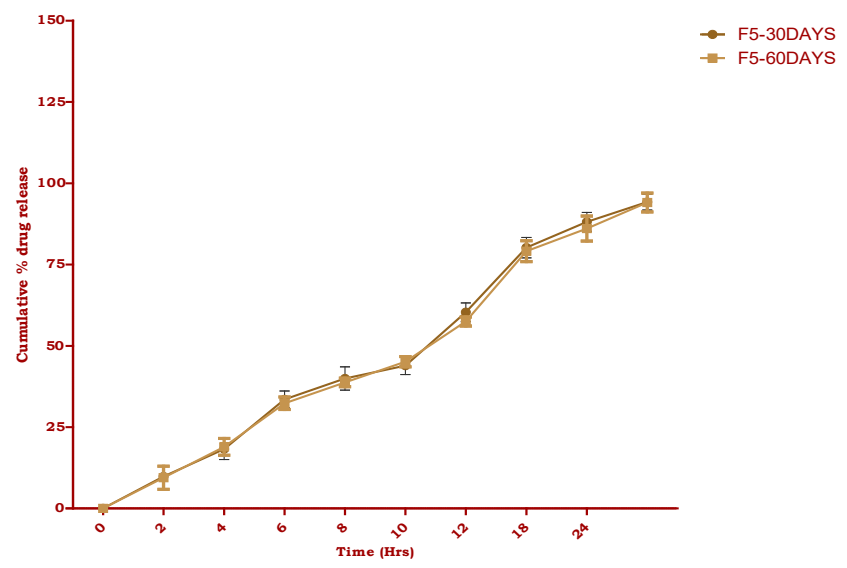

Figure 11: In vitro cumulative $\%$ of drug release studies of most satisfactory formulations (after stability); $n=3$, studies were repeated in triplicate, and the mean was calculated

Figure 11, it was confirmed that there were no substantial variations in physicochemical parameters and in vitro diffusion of the most satisfactory formulations (F5) after stability studies.

\section{DISCUSSION}

Transdermal patches of levosulpiride were successfully developed by HPMC E 15, Eudragit RL100, and Eudragit RS 100 using the solvent casting method. The developed transdermal patches hold the prerequisite physicochemical properties, such as, uniformity in drug content, weight, thickness, folding endurance, and moisture content. In vitro diffusion studies were conducted by using improved Franz diffusion cell with dialysis membrane as a permeation barrier. Formulation F5 (Eudragit RL 100-1\%, HPMC E 15-8\%) was found to be best among all batches of its consistent release rate for 12 hours and the extent of drug release $97.76 \%$. F5 was the most satisfactory formulations as it closely met the expected data and constantly permeated drug for 12 hours, which can preserve the preferred therapeutic concentration in plasma. F5 were subjected to short term stability studies which showed optimized results.

\section{CONCLUSION}

It was concluded from the present studies that the transdermal patches of levosulpiride were capable of exhibiting controlled release with the stability. Stability study of the formulations displayed no substantial changes in 
the concentration of drug, as well as, physical characteristics of the patches. The formulation (F5) had fulfilled the objectives of the present study, such as, increased bioavailability and reduced frequency of administration. Studies have indicated promising outcomes and there is a possibility for additional pharmacodynamics and pharmacokinetic assessment. There is a necessity to direct toxicity studies utilizing different experimental animals and assess the adequacy, safety, and efficacy of selected formulations.

\section{ACKNOWLEDGEMENT}

The authors are thankful to the Director and Dean of Anurag University (Anurag group of institutions), Hyderabad, for providing necessary facilities to carry out this work and all the material provided for development.

\section{REFERENCES}

1. Shivaraj A, Selvam RP, Mani TT, Sivakumar T. Design and evaluation of transdermal drug delivery of ketotifen fumarate. Int J Pharm Biomed Res. 2010;1:42-7.

2. Gupta JR, Tripathi P, Irchhiaya R, Garud N, Dubey P, Patel JR. Formulation and evaluation of matrix type transdermal patches of Glibenclamide. Int J Pharm Sci Drug Res. 2009;1:46-50.

3. Sanap GS, Dama GY, Hande AS, Karpe SP, Nalawade SV, Kakade RS. Preparation of transdermal monolithic systems of indapamide by solvent casting method and the use of vegetable oils as permeation enhancer. Int J Green Pharm. 2008;2:129-33.

4. Gannu R, Vishnu YV, Kishan V, Rao YM. Development of nitrendipine transdermal patches: In vitro and ex vivo characterization. Curr Drug Deliv. 2007;4:69-76.

5. Darwhekar G, Jain DK, Patidar VK. Formulation and evaluation of transdermal drug delivery system of clopidogrel bisulfate. Asian J Pharm Life Sci. 2011;1:270-8.

6. Sulpiride-DrugBank. Drugbank.ca. 2017[cited 12 May 2017]. Available from: https://www.drugbank.ca/drugs/DB00391.

7. Gupta S, Garg GR, Halder S, Sharma KK. Levosulpiride: A Review. Delhi psychiatry J. 2007;10(2):144-146.

8. Desai BG, Annamalai AR, Divya B, Dinesh BM. Effect of enhancers on permeation kinetics of Captopril for transdermal system. Asian J Pharm. 2008;35-7.

9. Kelvin CG, Anil JS, Prathik HS. Formulation and In vitro characterization of monolithic matrix transdermal system using HPMC/Eudragit S100 polymer blends. Int J Pharm Sci. 2009;1:108-20.
10. Peddapalli H, Ganta RP, Boggula N. Formulation and Evaluation of Transdermal Patches for Antianxiety Drug. Asian J Pharm. 2018;12(2):127-136.

11. Peddapalli $\mathrm{H}$, Chinnala KM, Banala N. Design and in vitro characterization of mucoadhesive buccal patches of duloxetine hydrochloride. Int J Pharm Pharm Sci. 2017;9:52-9.

12. Palem CR, Gannu R, Doodipala N, Yamsani VV, Yamsani MR. Transmucosal delivery of domperidone from bilayered buccal patches: in vitro, ex vivo and in vivo characterization. Arch Pharm Res. 2011;34(10):1701-10.

13. Reddy CP, Ramesh G, Shravan Kumar Y, Madhusudan RY. Development of bilayered Mucoadhesive Patches for buccal delivery of Felodipine: In vitro, ex vivo and in vivo characterization. Curr Trends Biotech Pharm. 2010; 4:673-683.

14. Jamakandi G, Mulla JS, Vinay BL, Shivakumar HN. Formulation, characterization, and evaluation of matrix-type transdermal patches of a model antihypertensive drug. Asian J Pharm. 2009;59-65.

15. Higuchi T. Mechanism of sustained action medication: Theoretical analysis of rate of release of solid drugs dispersed in solid matrices; J. Pharm. Sci. 1963;(52): 1145-1149.

16. Korsmeyer RW, Gurny R, Doelker E, Buri P, Peppas NA. Mechanism of solute release from porous hydro-matrices and other factors may be responsible, Int. J. Pharm. 1983;15: 25-35.

17. Suvakanta Dash, Padala Narasimha Murthy, Lilakanta Nath and Prasanta Chowdhury. Kinetic modeling on drug release from controlled drug delivery systems. Acta Poloniae Pharmaceutica Drug Research. 2010;67(3):217-223.

18. Peddapalli H, Dudhipala N, Chinnala KM, Banala N. Transmucosal Delivery of Duloxetine Hydrochloride for Prolonged Release: Preparation, in vitro, ex vivo Characterization and in vitro-ex vivo Correlation. Int J Pharm Sci Nanotech. 2018;11(5):29-4258

19. Yen WF, Basri M, Ahmad M, Ismail M. Formulation and Evaluation of Galantamine Gel as Drug Reservoir in Transdermal Patch Delivery System. The Sci World J. 2015;2:1-7.

20. Kumari PJ, Kumar GG, Kumar KS, Manasa B. Formulation and evaluation of transdermal drug delivery system for metoprolol tartarate. Int J Pharm Res and Dev. 2010; 2(4):1-6.

How to cite this article: Rajagoni A, Pagilla P, Perumala J, Puppala S, Peddapalli H, Sunand K, et al. Design and development of transdermal patches of antipsychotic drug: In vitro and ex vivo characterization. Int J Appl Pharm Sci Res.(2020);5(3): 45-53. doi: https://doi.org/10.21477/ ijapsr.5.3.2

Source of Support: Nil.

Conflict of Support: None declared. 